\title{
A best proximity point theorem for generalized Mizoguchi- Takahashi contractions
}

\author{
Pushpendra Semwal*, R.C. Dimri \\ Department of Mathematics, H.N.B.Garhwal University, Srinagar Garhwal, India \\ *Corresponding author E-mail: psrsdm@gmail.com
}

Copyright (C)2014 Pushpendra Semwal and R.C. Dimri. This is an open access article distributed under the Creative Commons Attribution License, which permits unrestricted use, distribution, and reproduction in any medium, provided the original work is properly cited.

\begin{abstract}
The purpose of this paper is to provide sufficient conditions for the existence of a unique best proximity point for generalized Mizoguchi- Takahashi contractions.Our paper provides an extension of a result due to Gordji and Ramezani[3].
\end{abstract}

Keywords: Fixed point, best proximity point, P-property, Mizoguchi- Takahashi contractions.

\section{Introduction}

Let $(X, d)$ be a metric space.Denote by $\mathrm{P}(\mathrm{X})$ the set of all nonempty subsets of $\mathrm{X}$ and $C B(X)$ the family of all nonempty closed and bounded subsets of X.A point $x$ in $\mathrm{X}$ is a fixed point of a multivalued map $T: X \rightarrow P(X)$, if $x \in T x$.Nadler [5] extended the Banach contraction principle to multivalued mappings.

Theorem 1.1 (5) Let $(X, d)$ be a complete metric spaces and let $T: X \rightarrow C B(X)$ be a multivalued map. Assume that there exists $r \in[0,1)$ such that

$H(T x, T y) \leq r d(x, y)$

for all $x, y \in X$, where $H$ is the Hausedorff metric with respect to $d$.Then $T$ has a fixed point.

The fixed point theory for multivalued mappings developed rapidly after the publication of Nadler's paper [5] in which he established a multivalued version of Banach's contraction principle. A huge number of generalizations of this principle appear in the literature. Particularly, the following generalization of Nadler's fixed point theorem due to Mizoguchi- Takahashi [4].

Theorem $1.2(4)$ Let $(X, d)$ be a complete metric space and $T: X \rightarrow C B(X)$ be a multivalued map. Assume that

$H(T x, T y) \leq \phi(d(x, y)) d(x, y)$

for all $x, y \in X$, where $\phi$ is a function from $[0, \infty)$ into $[0,1)$ satisfying limsup $\operatorname{st}^{+} \phi(s)<1$ for all $t \geq 0$. Then $T$ has a fixed point. 
Recently, Amini-Harandi and O'Regan [1] obtained a nice generalization of Mizoguchi and Takahashi's fixed point theorem. Throughout the article, let $\Psi$ be the family of all functions $\psi:[0, \infty) \rightarrow[0, \infty)$ satisfying the following conditions:

(a) $\psi(s)=0 \Longleftrightarrow \mathrm{s}=0$,

(b) $\psi$ is nondecreasing,

We denote by $\Phi$ the set of all functions $\phi:[0, \infty) \rightarrow[0,1)$ satisfying $\limsup _{r \rightarrow t^{+}} \phi(r)<1$ for all $t \geq 0$. Amini-Harandi and O'Regan generalized the Mizoguchi-Takahashi contraction condition (1) as follows:

Theorem $1.3(1)$ Let $(X, d)$ be a complete metric space and $T: X \rightarrow C B(X)$ be a multivalued map. Assume that $\phi(H(T x, T y)) \leq \phi(\psi(d(x, y))) \psi(d(x, y))$

for all $x, y \in X$, where $\psi \in \Psi$ is lower semicontinuous with limsup $\sin _{s+\frac{s}{\phi(s)}}<\infty$ and $\phi \in \Phi$. Then $T$ has a fixed point.

Very recently, Gordji and Ramezani [3] established a new fixed point theorem for a self map $T: X \rightarrow X$ satisfying a generalized Mizoguchi-Takahashi's condition in the setting of ordered metric spaces. The main result in [3] is the following.

Theorem 1.4 (3) Let $(X, d, \preceq)$ be a complete ordered metric space and $T: X \rightarrow X$ an increasing mapping such that there exists an element $x_{0} \in X$ with $x_{0} \preceq T x_{0}$. Suppose that there exists a lower semicontinuous function $\psi \in \Psi$ and $\phi \in \Phi$ such that

$\psi(d(T x, T y)) \leq \phi(\psi(d(x, y))) \psi(d(x, y))$.

for all $x, y \in X$ such that $x$ and $y$ are comparable. Assume that either $T$ is continuous or $X$ is such that the following holds: any $\preceq$-nondecreasing sequence $\left\{x_{n}\right\}$ with $x_{n} \rightarrow x$ implies $x_{n} \preceq x$ for all $n$. Then $T$ has a fixed point.

The aim of this paper is to give a generalization of the Theorem 1.4 by considering a non-self map T.

\section{Preliminary notes}

First, we present a brief discussion about a best proximity point.

Let $\mathrm{A}$ be a nonempty subset of ametric space $(\mathrm{X}, \mathrm{d})$ and $T: A \rightarrow X$ be a mapping. The solutions of the equation $T x=x$ are fixed point of $\mathrm{T}$.Consequently, $\mathrm{T}(\mathrm{A}) \cap \mathrm{A} \neq \emptyset$ is a necessary condition for the existence of a fixed point for the operator T.If this necessary condition does not hold, then $d(x, T x)>0$ for any $x \in A$ and the mapping $T: A \rightarrow X$ does not have any fixed point.In this setting, our aim is to find an element $x \in A$ such that $d(x, T x)$ is minimum in some sense. A point $x$ in A for which $d(x, T x)=d(A, B)$ is called a best proximity point of $\mathrm{T}$.

In our context, we consider two nonempty subsets $\mathrm{A}$ and $\mathrm{B}$ of a complete metric space and a mapping $T: A \rightarrow B$ satisfying a generalized Mizoguchi-Takahashi's condition and find a best proximity point of $\mathrm{T}$. We give an example to support our result.

Let $\mathrm{A}$ and $\mathrm{B}$ be two nonempty subsets of a metric space $(\mathrm{X}, \mathrm{d})$. We denote by $A_{0}$ and $B_{0}$ the following sets:

$A_{0}=\{x \in A: d(x, y)=d(A, B)$ for some $y \in B\}$,

$B_{0}=\{y \in B: d(x, y)=d(A, B)$ for some $x \in A\}$,

where $\mathrm{d}(\mathrm{A}, \mathrm{B})=\inf \{d(x, y): x \in A$ and $y \in B\}$.

$\operatorname{In}[6]$ authers present sufficient conditions which determine when the sets $A_{0}$ and $B_{0}$ are nonempty.

Definition 2.1 Let $A, B$ be two nonempty subsets of a metric space $(X, d)$. A mapping $T: A \rightarrow B$ is said to be a generalized Mizoguchi- Takahashi contractions if there exist $\phi \in \Phi$ and $\psi \in \Psi$ such that

$\psi(d(T x, T y)) \leq \phi(\psi(d(x, y))) \psi(d(x, y))$

for any $x, y \in A$. 
Definition $2.2(6)$ Let $(A, B)$ be a pair of nonempty subsets of a metric space $(X, d)$ with $A_{0} \neq \emptyset$. Then the pair $(A, B)$ is said to have the P-property if and only if for any $x_{1}, x_{2} \in A_{0}$ and $y_{1}, y_{2} \in B_{0}$,

$$
\left\{\begin{array}{l}
d\left(x_{1}, y_{1}\right)=d(A, B) \\
d\left(x_{2}, y_{2}\right)=d(A, B)
\end{array}\right\} \Longrightarrow d\left(x_{1}, x_{2}\right)=d\left(y_{1}, y_{2}\right)
$$

\section{Main results}

Theorem 3.1 Let $(A, B)$ be a pair of nonempty closed subsets of a complete metric space $(X, d)$ such that $A_{0}$ is nonempty. Let $T: A \rightarrow B$ be a continuous generalized Mizoguchi- Takahashi contraction mapping satisfying $T\left(A_{0}\right) \subset B_{0}$. Suppose that the pair $(A, B)$ has the P-property. Then there exists a unique $x^{*}$ in $A$ such that $d\left(x^{*}, T x^{*}\right)$ $=d(A, B)$.

Proof. Since $A_{0}$ is nonempty, we take $x_{0} \in A$.As $T x_{0} \in T\left(A_{0}\right) \subset B_{0}$, we can find $x_{1} \in A_{0}$ such that $d\left(x_{1}, T x_{0}\right)$ $=d(A, B)$.Similarly, since $T x_{1} \in T\left(A_{0}\right) \subset B_{0}$, there exists $x_{2} \in A_{0}$ such that $d\left(x_{2}, T x_{1}\right)=d(A, B)$. Repeating this process, we can get a sequence $\left\{x_{n}\right\}$ in $A_{0}$ satisfying

$d\left(x_{n+1}, T x_{n}\right)=d(A, B)$ for any $n \in N$

Since $(\mathrm{A}, \mathrm{B})$ has the P-property, we have that

$d\left(x_{n}, x_{n+1}\right)=d\left(T x_{n-1}, T x_{n}\right)$ for any $n \in N$.

Taking into account that $\mathrm{T}$ is a generalized Mizoguchi- Takahashi contraction, for any $n \in N$, we have that

$$
\begin{aligned}
\psi\left(d\left(x_{n}, x_{n+1}\right)\right) & \leq \phi\left(\psi\left(d\left(x_{n-1}, x_{n}\right)\right)\right) \psi\left(d\left(x_{n-1}, x_{n}\right)\right) \\
& \leq \psi\left(d\left(x_{n-1}, x_{n}\right)\right)
\end{aligned}
$$

Since $\psi$ is nondecreasing, we obtain

$d\left(x_{n}, x_{n+1}\right) \leq d\left(x_{n-1}, x_{n}\right)$

This means $d\left(x_{n}, x_{n+1}\right)$ is a non-increasing sequence of positive real numbers.Hence there exists $\mu \geq 0$ such that

$\lim _{n \rightarrow \infty} d\left(x_{n}, x_{n+1}\right)=\mu$

Since $\phi \in \Phi$, we have $\limsup _{r \rightarrow \mu} \phi(r)<1$.Then, there exist $\alpha \in[0,1)$ and $\epsilon>0$ such that $\phi(r) \leq \alpha$ for all $r \in[\mu, \mu+\epsilon)$. We can take $n_{0} \in N$ such that $\mu \leq d\left(x_{n}, x_{n+1}\right) \leq \mu+\epsilon$ for all $n \geq n_{0}$. Then for all $n \geq n_{0}$, we have

$\psi\left(d\left(x_{n}, x_{n+1}\right)\right) \leq \phi\left(\psi\left(d\left(x_{n-1}, x_{n}\right)\right)\right) \psi\left(d\left(x_{n-1}, x_{n}\right)\right)$

Letting $r \rightarrow \infty$ in the above inequality,we obtain that

$\psi(\mu) \leq \alpha \psi(\mu)$

Since $\alpha \in[0,1)$, this implies that $\mu=0$.Thus, we have

$\lim _{n \rightarrow \infty} d\left(x_{n}, x_{n+1}\right)=0$

Now we claim that the sequence $\left\{x_{n}\right\}$ is a Cauchy sequence. Since $\lim _{n \rightarrow \infty} d\left(x_{n}, x_{n+1}\right)=0$, it is sufficient to prove that $\left\{x_{2 n}\right\}$ is Cauchy sequence.

Suppose on the contrary that $\left\{x_{2 n}\right\}$ is not a Cauchy sequence. Then there exist $\epsilon>0$ and subsequences $\left\{x_{2 n_{k}}\right\}$ and $\left\{x_{2 m_{k}}\right\}$ of $\left\{x_{2 n}\right\}$ such that $n_{k}>m_{k}>k$ and

$d\left(x_{2 m_{k}}, x_{2 n_{k}}\right) \geq \epsilon$ 
and

$d\left(x_{2 m_{k}}, x_{2 n_{k-2}}\right)<\epsilon$

Now, from (4) and the triangle inequality, we get

$$
\begin{aligned}
\epsilon & \leq d\left(x_{2 m_{k}}, x_{2 n_{k}}\right) \\
& \leq d\left(x_{2 m_{k}}, x_{2 n_{k-2}}\right)+d\left(x_{2 n_{k-2}}, x_{2 n_{k-1}}\right)+d\left(x_{2 n_{k-1}}, x_{2 n}\right)
\end{aligned}
$$

Letting $k \rightarrow \infty$ and using (3),we get

$\lim _{k \rightarrow \infty} d\left(x_{2 m_{k}}, x_{2 n_{k}}\right)=\epsilon$

By the fact

$\left|d\left(x_{2 m_{k}}, x_{2 n_{k+1}}\right)-d\left(x_{2 m_{k}}, x_{2 n_{k}}\right)\right| \leq d\left(x_{2 n_{k}}, x_{2 n_{k+1}}\right)$

$\left|d\left(x_{2 m_{k-1}}, x_{2 n_{k}}\right)-d\left(x_{2 m_{k}}, x_{2 n_{k}}\right)\right| \leq d\left(x_{2 m_{k-1}}, x_{2 m_{k}}\right)$

using (3) and (6), we obtain

$\lim _{k \rightarrow \infty} d\left(x_{2 m_{k-1}}, x_{2 n_{k}}\right)=\lim _{k \rightarrow \infty} d\left(x_{2 m_{k}}, x_{2 n_{k+1}}\right)=\epsilon$

Moreover, from

$\left|d\left(x_{2 m_{k-1}}, x_{2 n_{k+1}}\right)-d\left(x_{2 m_{k-1}}, x_{2 n_{k}}\right)\right| \leq d\left(x_{2 n_{k}}, x_{2 n_{k+1}}\right)$

and combining with (3) and (9), we conclude that

$\lim _{k \rightarrow \infty} d\left(x_{2 m_{k-1}}, x_{2 n_{k+1}}\right)=\epsilon$

from (9), we coclude that

$$
\begin{aligned}
& \lim _{k \rightarrow \infty} d\left(T x_{2 m_{k-1}}, T x_{2 n_{k}}\right)=\epsilon \\
& \begin{aligned}
\psi\left(d\left(x_{2 m_{k}}, x_{2 n_{k+1}}\right)\right) & =\psi\left(d\left(T x_{2 m_{k-1}}, T x_{2 n_{k}}\right)\right) \\
& \leq \phi\left(\psi\left(d\left(x_{2 m_{k-1}}, x_{2 n_{k}}\right)\right) \psi\left(d\left(x_{2 m_{k-1}}, x_{2 n_{k}}\right)\right)\right.
\end{aligned}
\end{aligned}
$$

Letting $k \rightarrow \infty$ and using (2) and (12), we have

$\psi(\epsilon) \leq \alpha \psi(\epsilon)$

a contradiction. Therefore, $\left\{x_{n}\right\}$ is a Cauchy sequence. Since $\left\{x_{n}\right\} \subset A$ and $\mathrm{A}$ is closed subset of a complete metric space $(\mathrm{X}, \mathrm{d})$, we can find $x^{*} \in A$ such that $x_{n} \rightarrow x^{*}$.

Since $\mathrm{T}$ is continuous, we have $T x_{n} \rightarrow T x^{*}$. Taking into account that the sequence $\left(d\left(x_{n+1}, T x_{n}\right)\right)$ is a constant sequence with value $\mathrm{d}(\mathrm{A}, \mathrm{B})$, we deduce

$d\left(x^{*}, T x^{*}\right)=d(A, B)$.

This means that $x^{*}$ is a best proximity point of T. For uniqueness, suppose that $x_{1}$ and $x_{2}$ are two best proximiy points of $\mathrm{T}$ with $x_{1} \neq x_{2}$. This means that

$d\left(x_{1}, T x_{1}\right)=d(A, B)$

$d\left(x_{2}, T x_{2}\right)=d(A, B)$

Using the P-property, we have

$d\left(x_{1}, x_{2}\right)=d\left(T x_{1}, T x_{2}\right)$

Again, T is generalized Mizoguchi- Takahashi contraction, we have

$\psi\left(d\left(x_{1}, x_{2}\right)\right)=\psi\left(T x_{1}, T x_{2}\right) \leq \phi\left(\psi\left(d\left(x_{1}, x_{2}\right)\right)\right) \psi\left(d\left(x_{1}, x_{2}\right)\right) \leq \alpha \psi\left(d\left(x_{1}, x_{2}\right)\right)$

a contradiction. Therefore, $x_{1}=x_{2}$. 
Corollary 3.2 Let $(A, B)$ be a pair of nonempty closed subsets of a complete metric space $(X, d)$ such that $A_{0}$ is nonempty. Let $T: A \rightarrow B$ be a continuous mapping satisfying $T\left(A_{0}\right) \subset B_{0}$, and Mizoguchi- Takahashi contraction condition $d(T x, T y) \leq \phi(d(x, y)) d(x, y)$ for any $x, y \in A$. Suppose that the pair $(A, B)$ has the P-property. Then there exists a unique $x^{*}$ in $A$ such that $d\left(x^{*}, T x^{*}\right)=d(A, B)$.

Example 3.3 Consider $X=\Re^{2}$ with the usual metric.

Let $A$ and $B$ be the subsets of $X$ defined by

$A=\{0\} \times[0, \infty)$ and $B=\{1\} \times[0,1)$.

Obviously $d(A, B)=1$ and $B$ is not closed subset of $X$.

Note that $A_{0}=0 \times[0,1)$ and $B_{0}=B$.

We consider the mapping $T: A \rightarrow B$ defined as

$d(0, x)=\left(1, \frac{x}{1+x}\right)$ for any $(0, x) \in A$.

In the sequel, we check that $T$ is generalized Mizoguchi- Takahashi contraction.

In fact, for $(0, x),(0, y) \in A$ with $x \neq y$, we have

$$
\begin{aligned}
d(T(0, x), T(0, y)) & =d\left(\left(1, \frac{x}{1+x}\right),\left(1, \frac{y}{1+y}\right)\right) \\
& =\left|\frac{x}{1+x}-\frac{y}{1+y}\right| \\
& =\left|\frac{x-y}{(1+x)(1+y)}\right| \\
& \leq \frac{|x-y|}{1+|x-y|} \\
& =\phi(\psi(d((0, x),(0, y))) \psi(d((0, x),(0, y))) .
\end{aligned}
$$

Where $\psi(t)=t$ for $t>0$ and $\phi(t)=\frac{1}{1+t}$ with limsup $_{r \rightarrow t^{+}} \phi(r)<1$ for $t \geq 0$.

Notice that the pair $(A, B)$ satisfies the P-property.

Indeed, if

$d\left(\left(0, x_{1}\right),\left(1, y_{1}\right)\right)=\sqrt{1+\left(x_{1}-y_{1}\right)^{2}}=d(A, B)=1$,

$d\left(\left(0, x_{2}\right),\left(1, y_{2}\right)\right)=\sqrt{1+\left(x_{2}-y_{2}\right)^{2}}=d(A, B)=1$,

then $x_{1}=y_{1}$ and $x_{2}=y_{2}$ and consequently,

$d\left(\left(0, x_{1}\right),\left(0, x_{2}\right)\right)=\left|x_{1}-x_{2}\right|=\left|y_{1}-y_{2}\right|=d\left(\left(1, y_{1}\right),\left(1, y_{2}\right)\right)$.

By Theorem 3.1, T has a unique best proximity point.

Obviously, the point $(0,0) \in A$ is a unique best proximity point for $T$, since

$d((0,0), T(0,0))=d((0,0),(1,0))=1=d(A, B)$

If $(0, x) \in A$ is a best proximity point for $T$, then

$1=d(A, B)=d((0, x), T(0, x))=d\left((0, x),\left(1, \frac{x}{1+x}\right)\right)=\sqrt{1+\left(x-\frac{x}{1+x}\right)^{2}}$,

and this gives us

$\left(x-\frac{x}{1+x}\right)=0$

the solution of (12) is $x=0$ and is unique.Hence $(0,0) \in A$ is unique best proximity point for $T$. 


\section{References}

[1] A. Amini-Harandi, and D. O'Regan , "Fixed point theorem for set-valued contraction type maps in metric spaces", Fixed Point Theory and Appl, Vol.7, 2010, (2010), Article ID 390183.

[2] A. A. Eldred, P. Veeraman, " Existence and convergence of best proximity points", J.Math.Anal. Appl, Vol.323, (2006), pp.1001-1006.

[3] M. E.Gordji, M. Ramezani , "A generalization of Mizoguchi and Takahashi's theorem for single-valued mappings in partially ordered metric spacesr", Nonlinear Anal, Vol.74, (2011), pp.4544-4549.

[4] N. Mizoguchi and W. Takahashi, "Fixed point theorems for multivalued mappings on a complete metric space", J. Math. Anal. Appl., Vol.141, (1989), pp.177-188.

[5] S.B. Nadler, "Multivalued contraction mappings", Pacific j.Math, Vol.30, (1969), pp.475-488.

[6] V. Sankar Raj, A best proximity point theorem for weakly contractive non-self-mappings, Nonlinear Analysis, vol.74 (2011), 4804-4808. 